Article

\title{
Channel Choice Determinants of (Digital) Government Communication: A Case Study of Spatial Planning in Flanders
}

\author{
Willemien Laenens *, Wendy Van den Broeck and Ilse Mariën \\ Studies in Media, Innovation and Technology, imec Brussels, Vrije Universiteit Brussel, 1050 Brussels, Belgium; \\ E-Mails: willemien.laenens@vub.be (W.L.), wendy.van.den.broeck@vub.be (W.V.d.B..), ilse.marien@vub.be (I.M.) \\ * Corresponding author
}

Submitted: 29 June 2018 | Accepted: 21 September 2018 | Published: 21 December 2018

\begin{abstract}
Governments at all levels believe the digitisation of their services and increased interaction with citizens will bring significant advantages in terms of transparency, creation of public value, and improvement of government performance (Al-Hujran, Al-Debei, Chatfield, \& Migdadi, 2015). Nonetheless, this evolution towards more digital services and communication by governments raises questions in terms of inclusivity and accessibility. We conducted focus groups with a heterogeneous panel of over 80 citizens, ranging from non-users of digital technologies to high-level users, to study their choice of channel and their perception towards the evolving digitisation of communication and services, applied to the case of spatial planning in Flanders (Belgium). The results reveal that the most decisive channel choice determinants in spatial planning relate to the channel characteristics themselves, the information, the contextual aspect of the communication flow, and digital inequality mechanisms; meaning that (a) citizens opt for local communication channels when interacting with local, regional, and national governments, (b) citizens prefer to be personally informed when the communicated message has a direct impact on them, and (c) more vulnerable digital profiles consider the transition to digital communication by default as problematic.
\end{abstract}

\section{Keywords}

channel choice; digital by default; government communication; government services; media user profiles; public services; spatial planning

Issue

This article is part of the issue "E-Government and Smart Cities: Theoretical Reflections and Case Studies", edited by Peter Mechant (Ghent University, Belgium) and Nils Walravens (Vrije Universiteit Brussel, Belgium).

(C) 2018 by the authors; licensee Cogitatio (Lisbon, Portugal). This article is licensed under a Creative Commons Attribution 4.0 International License (CC BY).

\section{Introduction}

The digitisation of government services and communication is believed to bring many advancements regarding transparency, creation of public value, and improvement of government performance (Al-Hujran, Al-Debei, Chatfield, \& Migdadi, 2015). E-Government is not a new phenomenon. Since the beginning of the 21st century, governments have been exploring the potential of information and communication technologies (ICTs) in their daily functioning (Prins, 2001; Zakareya \& Zahir, 2005). More recently, there has been a shift from e-government to open governments and smart cities. This shift not only includes the digitisation of services and communication, but considers the digitisation process as a means to deal with diverse urban and societal problems in cities. This move is supported by governments as well as the private and public sector. Each one aspires to take part in this movement by experimenting with and developing diverse new digital tools and services (e.g., open government, open data), accompanied with a customised digital communication strategy to enable bottom-up information production and sharing (Hansson, Belkacem, \& Ekenberg, 2015). 
In the Flemish region (Belgium), the "Radicaal Digitaal" (radically digital) campaign was launched in 2015, which strives for a pursued digitisation in the services and communication strategy of the different government departments by 2020 . Although this might seem a sound strategy to rationalise governmental services, there are potential barriers. In Flanders, one in ten citizens has no internet connection at home (Vanhaelewyn \& De Marez, 2017). In 2017, 61\% of the Belgian population had general digital skills, going from the basic level to a more advanced level (Federale Overheidsdienst Economie, K.M.O., Middenstand en Energie, 2017). Despite issues concerning access and digital skills decrease, and many organisations aim to improve these issues among their target groups (e.g., via public access in libraries) (Mariën \& Vleugels, 2011), some citizens are still digitally excluded and a digital-bydefault strategy may have severe consequences for them. A key question is whether the perceived advantages of a digital government foster the promised benefits for all citizens. Despite the great belief in digital services, governments at all levels face low use of these services due to challenges regarding both supply (e.g., management support, IT infrastructure) and demand (e.g., trust, usefulness, skills) (Al-Hujran et al., 2015; Anthopoulos, Reddick, Giannakidou, \& Mavridis, 2016).

The demand-side is referred to as channel choice or elements influencing a citizen's decision-making process when opting for particular communication channels for their interaction with governments (Ebbers, Pieterson, \& Noordman, 2007). The literature on channel choice is scarce and its exact influence is rarely measured (Pieterson \& van Dijk, 2007). Therefore, updated research on channel choice of (e-)government services is needed.

We, therefore, provide a case study on government communication channels for spatial planning in Flanders, based on a commissioned study (Laenens, Vanderstraeten, Braet, Mariën, \& Van den Broeck, 2017) by the Department of Environment and Spatial Development (Department) and the Department of Public Governance and the Chancellery of the Flemish Government that aimed to evaluate and improve their communication strategies. Spatial planning makes an interesting case, as it concerns information that can be both very close to citizens (e.g., concerning their own street or village) or further away (e.g., concerning more remote projects). Communication in spatial planning is mostly one-way communication. The Department distributes information via a range of channels such as newspaper advertisements, Twitter, posters, the Belgian Official Gazette, government websites, information events, messages in municipal information sheets, commercials on public radio and television, and registered letters. The only interaction between the Department and citizens is via so-called participatory meetings, where citizens are invited to give ideas and feedback on a certain area.
Consequently, this article will answer the following two questions: which elements influence citizens' channel choice for spatial planning? Would citizens embrace a move towards digital channels in spatial planning or do they see too many barriers?

We first provide an in-depth literature study on the need for inclusive communication in regard to digitising governments. Second, a framework on channel choice is deducted from literature. Third, we use qualitative data-focus groups with diverse projective techniquesto answer the research questions. Finally, we present the results, discussion, and conclusion.

\section{Inclusive Communication in a Context of Digitising Governments}

Sanders and Canel (2013, p. 4) define government communication as communication by public institutions that is executive in the services of political reasoning and aims to enact the will of citizens. This definition, however, lacks a particular scope on the flows of communication. Traditional communication tools (e.g., telephone and front desk), though still relevant today, limit the information flow as interactive communication between governments and citizens is impossible. With the emergence of ICTs, public services and communication became more efficient (Gil-Garcia \& Martinez-Moyano, 2007; Reddick, 2005b; Verdegem \& Verleye, 2009). They were hoped to even foster greater interactivity and participation (Dugdale, Daly, Papandrea, \& Maley, 2005). But this became only widely discussed after the emergence of digital technologies (e.g., social media, mobile applications) as they enable governments to open up and become innovative and collaborative (Hansson et al., 2014). They are believed to bring benefits in terms of transparency, participation, and accountability as well (Hansson et al., 2014; Harrison \& Sayogo, 2014; Wijnhoven, Ehrenhard, \& Kuhn, 2015). However, the potential of open governments is often taken for granted. Critics express their concerns regarding privacy and risk, trust, the design of the platform, etc. (Lourenço, 2015; Wijnhoven et al., 2015).

This critical reflection is also apparent in the field of spatial planning. Technologies are believed to bring more openness to planning activities, more participation of citizens, and opportunities to collaborate (Criado, SandovalAlmazan, \& Gil-Garcia, 2013; Meijer \& Torenvlied, 2014). Social media and mobile technologies enable citizens with an internet connection to receive information whenever and wherever they want, and to participate online and generate their own content (Kleinhans, van Ham, \& Evans-Cowley, 2015). However, there is still an overrepresentation of informing and reporting applications and a lack of successful participatory applications (Ertiö, 2015). The emergence of social media and mobile communication in the field also poses additional challenges (e.g., to guarantee the quality of online information, how to create a trustful relationship, etc.) (Afzalan \& EvansCowley, 2015). Government agencies need to deal with 
disaffection online, instead of just spreading online announcements (Schweitzer, 2014). Digitisation also goes hand in hand with digital inequality mechanisms, posing a threat to those who lack access or skills (Kleinhans et al., 2015; Reddick \& Anthopoulos, 2014; Williamson \& Ruming, 2017).

Digital inequalities were believed to have a major influence on the uptake of e-services (van Dijk, Pieterson, van Deuren, \& Ebbers, 2007). Van Deursen, van Dijk and Ebbers (2006) identified a number of building blocks for successful e-services: accessibility, user-friendliness, and a multi-channel approach. The latter highlights the importance of communicating through several, both offline and online, channels to ensure no citizen is set aside because of his or her lack of digital media usage (Dugdale et al., 2005).

To counter digital exclusion mechanisms, our study is based upon a conceptual framework that distinguishes different media profiles and how each of these profiles is confronted, or not, with digital exclusion (Mariën \& Baelden, 2015). This framework, entitled "8 profiles of digital inequalities" distinguishes 8 media profiles based upon 13 key indicators, of which 5 are in the social field (i.e., income, education, participation in life domains, agency, and well-being) and 8 in the digital field (i.e., access, attitude, digital skills, social and soft skills, autonomy of use, user practices, media richness of the environment, and support networks). The framework emphasises that there is not a clear-cut distinction between digitally included and digitally excluded persons, but that digital exclusion is a fragmented phenomenon defined by how the 13 indicators interact. We targeted each of the 8 profiles in this study, which enabled us to include the wants and needs of non-users to high-level users.

\section{Channel Choice in Government Communication}

In order to answer the question of why citizens would opt for a particular government channel, the factors influencing their decision-making process were studied in detail. Channel choice literature is inspired by disciplines such as Media Richness Theory (Daft \& Lengel, 1986) and theories on technology acceptance and use (Aizen, 1991; Davis, 1989; Fishbein \& Aizen, 1975; Rogers, 2003; Venkatesh \& Davis, 2000; Venkatesh, Morris, Davis, \& Davis, 2003), although they do not specifically focus on (e-)government channels. The literature on channel choice itself is mostly concentrated on the comparison between websites, telephone, front desk, and e-mail (Pieterson, 2009, 2010; Reddick \& Turner, 2012). However, the focus on new digital media is increasingly gaining attention (Mergel \& Bretschneider, 2013; Reddick \& Anthopoulos, 2014).

Channel choice is an individual and continuing process: when citizens have had a bad experience with a channel, they will look for another one that meets their needs (Pieterson \& Ebbers, 2008). Pieterson (2009) confirms and expands this as citizens initially opt for habit- ual decision-making (i.e., based on previous experiences) and only when they are not satisfied with their choice, will they think about this (i.e., based on finding a match between the envisioned task and the most appropriate channel). According to Pieterson (2009), several determinants influence which decision-strategy is being followed. He groups these determinants into four main categories: personal characteristics, channel characteristics, task characteristics, and situational characteristics.

Socio-demographic elements (e.g., gender, age, educational level) influence channel choice (Ebbers et al., 2007; Plattfaut et al., 2013; Reddick \& Turner, 2012). Reddick and Turner (2012) position these elements in the broader context of 'digital divide and demographics' because they have a direct impact on the access and use of e-government channels. However, because digital inequality mechanisms are so important for the choice between e-services and offline government services, we position these elements into a new category (see below). Ethnicity, daily Internet use, being a government employee, income, having a disability, and the size of a person's network might also play a role (Reddick \& Turner, 2012), just as individual preferences regarding the use of traditional or digital media (Pieterson \& van Dijk, 2007). Personal characteristics can exert influence on all other determinants and are, therefore, considered as very decisive.

Channel characteristics relate to the (perceived) performance of public services (Ebbers et al., 2007; Hung, Chang, \& Kuo, 2013; Pieterson, 2010). Over the years, many of these characteristics were presented and a broad set of determinants is known today, but their influence still needs to be further studied (Bagozzi, 2007). The most referred channel characteristics are perceived usefulness and perceived ease of use (Davis, 1989). Though Davis's technology acceptance model (1989) was thoroughly criticised and edited over the years (Bagozzi, 2007), it is still relevant in the discussion on channel choice. Aizen (1991) adds perceived behavioural control, which consists of self-efficacy and controllability. In his diffusion of innovations theory, Rogers (2003) stresses the importance of compatibility or to what extent an innovation is perceived as consistent with previous experiences and current beliefs and norms. Ohme (2014) identified perceived risk in his m-government acceptance research model. Lastly, Pieterson (2009) adds speed (contact speed and feedback speed), personalisation of services, level of interactivity, tangibility, and accountability to these characteristics.

When a task is perceived as rather complex or ambiguous, citizens prefer personal contact (e.g. telephone, front desk) and the Internet for more effortless tasks (Ebbers et al., 2007; Pieterson \& van Dijk, 2007). Reddick (2005a) found that although citizens achieve their desired outcomes when using the telephone, they are not necessarily satisfied with this type of contact. These findings are in line with Media Richness Theory (Daft \& Lengel, 1986) which states that some media are better 
suited to transmit information based on the level of uncertainty and ambiguity. The type of task is also important, as citizens prefer to go online for collecting information, whereas they prefer the telephone or a front desk for solving problems (Reddick \& Anthopoulous, 2014; Reddick \& Turner, 2012)

Situational characteristics refer to constraints such as the availability of the channel, practical restrictions (e.g., time, distance), emotions when choosing a channel, efficiency (i.e., balance between effort and invested time), effectiveness (e.g., need for closure) and trust in government (Ebbers et al., 2007; Ebbers, Jansen, \& van Deursen, 2016; Pieterson, 2009, 2010; Reddick, 2005b). According to the unified theory of acceptance and use of technology (Venkatesh et al., 2003), four elements can be added: performance expectancy, effort expectancy, social influence, and facilitating conditions. The first three determinants influence a user's behavioural intention, while facilitating conditions are directly linked to usage behaviour. They also identified four elements moderating the impact of these determinants: age, gender, experience, and voluntariness of use (Venkatesh et al., 2003).

Digital inequality mechanisms, such as material access, motivation, digital skills, diversity, and intensity of use might influence channel choice (Almuwil, Weerakkody, \& El-Haddadeh, 2011; Helsper, 2012; Helsper \& Reisdorf, 2013; van Dijk, 2006). These mechanisms were believed to have a major influence on the uptake of e-government services (van Dijk et al., 2007). However, they have a greater influence on the perceived satisfaction of citizens regarding e-services (Ebbers et al., 2016). Trust in digital media can also influence channel choice as a negative attitude towards Internet, and ICTs may lead to limited use of e/m-services (Helsper, 2012; Hung et al., 2013).
Channel choice and its role in spatial planning has not been deeply discussed. Most research focuses on the benefits and hindrances of both traditional and technological channels in spatial planning (Evans-Cowley \& Hollander, 2010; Trapenberg Frick, 2016; Williamson \& Ruming, 2017), but does not reveal which elements influence citizens' decision-making process when choosing a channel. This study, therefore, proposes a conceptual framework summarising the identified determinants based on our literature review (see Table 1). We will analyse which of these determinants indeed played a role in the decision-making process of our respondents. Note that this table does not highlight causal relationships as this is not the goal of the study.

\section{Methods and Data Analysis}

A qualitative research study was performed to identify (1) participants' channel choice determinants of channels used for spatial planning in Flanders, and (2) their opinion and perception towards digital communication in spatial planning. 10 focus groups were conducted with a total of 86 participants between 18 and 79 years old (mean of 46 years) of which $36 \%$ male, $64 \%$ female respondents. Considering the educational level, we reached both higher-educated as well as lower-educated citizens (see Figure 1).

Focus groups enable one to efficiently gather information of a group of people. The group aspect allows for rich interactions between the participants, as they can build further onto each other's answers and are encouraged to talk about matters that are evident and would otherwise not be mentioned. Contradictory responses can immediately be discussed (Stewart \& Shamdasani, 1990).

Table 1. Conceptual framework of channel choice.

\begin{tabular}{ll}
\hline Personal characteristics & Situational characteristics \\
- socio-demographic elements & - availability \\
\hline Channel characteristics & - practical constraints \\
- perceived usefulness & $\bullet$ social influence \\
- perceived ease of use & $\bullet$ effectiveness \\
- perceived behavioural control & - trust in government \\
- compatibility & - facilitating conditions \\
- perceived risk & $\bullet$ efficiency \\
- speed & Digital inequality mechanisms \\
- personalization of services & $\bullet$ access \\
- level of interactivity & $\bullet$ skills \\
- tangibility & $\bullet$ motivation \\
- accountability & $\bullet$ diversity of use \\
\hline Task characteristics & $\bullet$ intensity of use \\
- complexity & $\bullet$ belief in digital \\
- ambiguity & \\
- type of task & \\
- uncertainty & \\
\hline
\end{tabular}




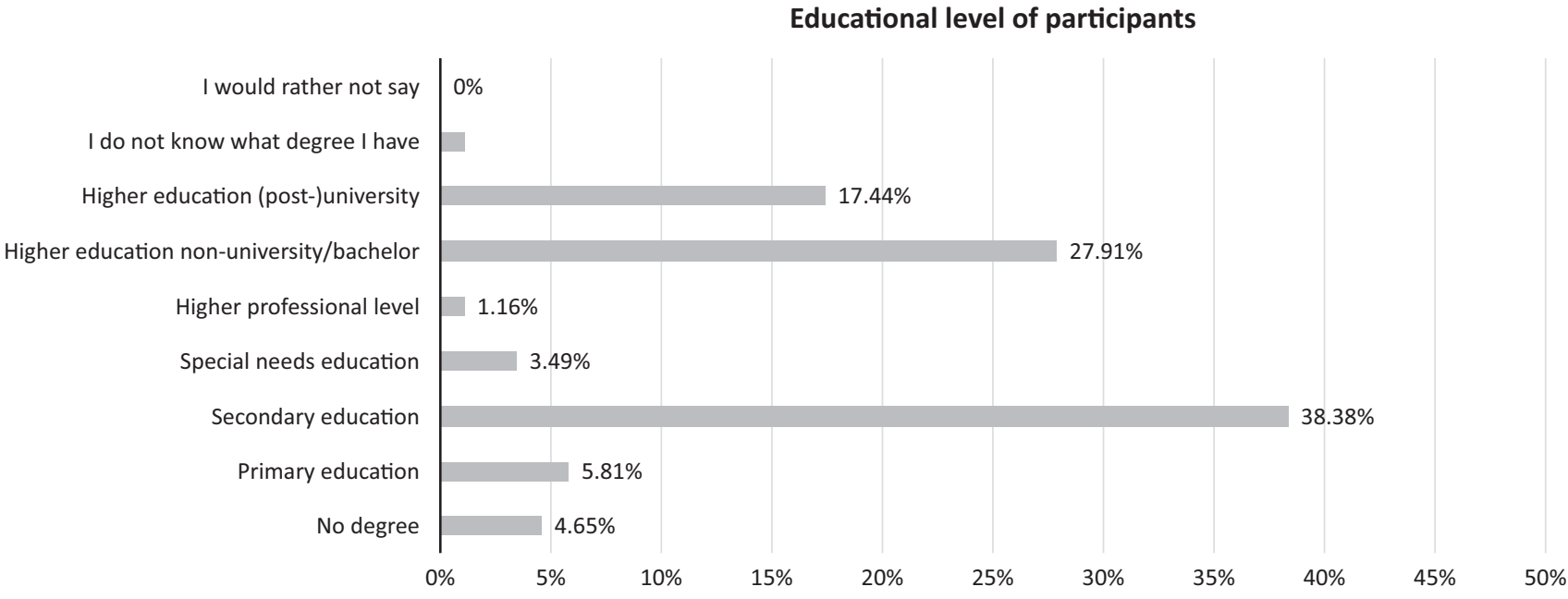

Figure 1. Educational level of participants.

A purposeful sampling was applied (Sandelowski, 1995). Recruitment criteria included a mixture of sociodemographic profiles and a diversity of media possession, usage, and skills in line with the 8 media profiles of Mariën and Baelden (2015). The focus groups were held at different socio-cultural organisations, including poverty organisations and universities. They were organised all over Flanders to avoid geographical sampling bias.

Every focus group lasted approximately two hours and a video and audio recording was made to process the data afterward. The focus groups were guided by a semistructured topic list. We applied a grounded theory approach (Glaser \& Strauss, 1967) for the data analysis. Participants also had to fill in a quantitative self-assessment test based on the 8 profiles of digital inequalities (Mariën \& Baelden, 2015) to examine their exposure to digital inequality mechanisms and determine their media profile.

\section{Results}

This section outlines the main findings of the case study. First, we present an overview of the channel choice determinants for spatial planning, and then we examine how citizens perceive the move towards digital communication strategies.

\subsection{Channel Choice Determinants for Spatial Planning in Flanders}

Based on the results, the conceptual framework (see Table 2) was modified. Several determinants of the original framework were not mentioned and thus removed from the framework. Newly mentioned determinants were added in italics. In the next section, we will only concentrate on the (new) determinants mentioned by our participants.

\subsubsection{Personal Characteristics}

In literature, personal characteristics were seen as very decisive because they influence all other determinants. However, only age and educational level were mentioned in the focus groups. Some participants especially had trouble with digital channels because they felt too old to use them or lacked the necessary skills. Also, digitally literate participants expressed these concerns with regards to other individuals, such as their parents. This is partly due to the age bias people have with regard to digital media use. The idea that all youngsters are digital natives and elderly people do not master digital tools is still present today. The influence of one's educational level was seen as decisive because of the language complexity and legislative character of the specific content in spatial planning.

"For the older generation, these things [digital media] are all new and very different, which makes it harder for them." (Female)

"This is primarily [written] for intellectuals and professionals, not for Joe Public." [about the Belgian Official Gazette] (Female)

\subsubsection{Channel Characteristics}

According to the results, we can distinguish diverse channel characteristics, as some characteristics are more concentrated on the look and feel of the channels (i.e., design, professional level of the channel, accountability), while others refer to the presence of the channels (i.e., knowledge of existence, interconnectedness, cost), their usability and user-friendliness (i.e., perceived usefulness, perceived ease of use, tangibility), and the negative perception of our participants towards these channels (i.e., perceived risk). 
Table 2. Modified conceptual framework of channel choice.

\section{Personal characteristics}

- socio-demographic elements

\section{Channel characteristics}

- perceived usefulness

- perceived ease of use

- perceived behavioural control

- compatibility

- perceived risk

- speed

- personalization of services

- level of interactivity

- tangibility

- accountability

- cost

- professional level

- knowledge of existence

- design

\section{Task characteristics}

- complexity

- ambiguity

- type of task

- uncertainty

\section{Situational characteristics}

- availability

- practical constraints

- emotions

- social influence

- effectiveness

- trust in government

- facilitating conditions

- efficiency

\author{
Digital inequality mechanisms \\ - access \\ - skills \\ - motivation \\ - diversity of use \\ - intensity of use \\ - belief in digital
}

\section{Information characteristics \\ - information quality \\ - information quantity \\ - comprehensibility \\ - proximity level \\ - governance level}

\section{- Look and feel}

The design (e.g., graphical elements, content and used materials) of the channels was heavily discussed and evaluated. Respondents particularly suggested improving the design of the Belgian Official Gazette, the poster, and the posts on social media by making the content more clear, readable (e.g., less text), and attractive (e.g., less legislation, more visuals).

"There is so much on that poster that you cannot see the wood from the trees." (Female)

"That font, Times New Roman [laughter]." (Female)

Second, participants believed the Belgian Official Gazette was more for professional use because of the language and content, so the channel was not popular among our respondents.

Lastly, they mentioned the differing accountability of the channels. Generally, a registered letter includes a clear sender and receiver and feels, therefore, more official and personal, definitely in contrast to an e-mail which is perceived as less reliable because of the many advertisements and digital newsletters. Some wanted to choose through which channel (i.e., post or e-mail) they received information themselves. We, therefore, recommend the option to unsubscribe from channels in spatial planning.
"Getting information by post is definitely more official. E-mail, there you also receive a lot of advertising." (Male)

"It's important that direct communication is personally addressed, with your name on it, so people feel more affected and perhaps feel the need to speak up." (Female)

\section{- Presence}

Many participants did not know certain channels existed (e.g., Belgian Official Gazette, poster, and Twitter). According to them, this can be solved by connecting these channels to a better-known channel (interconnectedness). The distinction between an information event (i.e., communicating the made decision) and a participatory meeting (i.e., giving ideas, suggestions) was also not clear, which might explain the frustration among participants that their voices are often not heard in "those meetings."

"You might also want to link up to it sooner, nobody knows you can read it in the Belgian Official Gazette, so you need to put the Belgian Official Gazette itself in the picture." (Female)

They also indicated that some information on spatial planning can only be read after paying for the channel itself (i.e., newspaper advertisement) (cost of the channel). For some, newspapers provide little information, in gen- 
eral, so they do not see the benefit of paying for it. Consequently, a newspaper advertisement on spatial planning might not be the best channel to communicate, as newspapers are not for free and not always perceived as interesting.

"I think a newspaper is quite expensive for the amount of information that you can find in it." (Male)

\section{- Usability and user-friendliness}

Participants suggested the provision of search engines and the availability of filtering information via hashtags could improve the perceived ease of use of government websites for spatial planning. Such tools are strongly related to the type of information people are interested in. In the case of spatial planning, this is about the proximity towards their own region of interest (i.e., where they live, work, etc.).

"Search engines are an added value for government websites." (Male)

"But that you can really select this is my region, give me a notification if something happens within my region, or that you can filter according to your interests, for example, if environmental issues are of interest to you." (Female)

Participants disagreed on the perceived usefulness of social media and government websites especially. Since we reached both low-level and high-level users of digital technologies, this is not surprising. Advanced digital profiles believed social media and government websites would bring benefits regarding access to information (e.g., they would no longer have to go to the town hall to look into the plans), while low-level digital profiles are still confronted with lack of access, skills, etc. to efficiently use these channels. They perceive analogue channels as easier to use, partly due to their tangibility (i.e., having it on paper feels more official). This is, of course, not in line with the pursued digital approach by governments.

"You should be able to access the plans of spatial planning online. There should be a database, so you can at least prepare yourself [for an information meeting] at home in front of your computer." (Female)

"I would like to receive this type of information, preferably by post or municipal information sheet, so it is comfortable to read." (Female)

\section{- Negative perception}

Some participants expressed concerns about their privacy when using social media (perceived risk). If the Department wishes to further utilise social media, it needs to guarantee a safe and trusted environment where citizens can share ideas and thoughts.

"I do have a lot of distrust about receiving things in a digital manner.... Receiving information by post is a bit more official anyway." (Male)

"I think social media is harmful to my privacy." (Female)

\subsubsection{Task Characteristics}

Task characteristics were not found to be important, probably because information on spatial planning in Flanders is mostly communicated from a top-down perspective, hence paying less attention to bottom-up approaches. However, our participants want to have a voice in this discussion and state that more bottom-up initiatives are needed. Apart from the information event and participatory meeting, the potential of social media in spatial planning in Flanders should be explored as it enables, when used in the right conditions, more diverse interaction and active participation.

\subsubsection{Situational Characteristics}

Our participants reported having doubts about the policies and the implementation of spatial planning in Flanders (trust in government) and consequently did not trust the effectiveness of particular channels (e.g., information event, participatory meeting). They questioned the relevance of participatory meetings, as they have the idea that everything is already planned and decided and, therefore, they have no real voice. As aforementioned, this might be because the distinction between an information event and a participatory meeting is vague.

"I have not been to such a meeting yet, because it does not make sense. Everything has been done and decided already." [about the participatory meeting] (Female)

Respondents also questioned the availability of certain channels, as for example, not everyone had received the municipal information sheet with information on the planned works. Consequently, some participants were frustrated because they were not prepared to adapt to the adjustments due to these works (i.e., fewer parking spots, more detours). Another issue concerning the availability of channels is practical constraints (e.g. distance). This is especially true for the poster as it needs to be put up in the actual location where the works will take place, and not everyone passes through that area.

"But if you do not pass by, you do not see it and you have to stop to read it too." [about the poster] (Female) 


\subsubsection{Digital Inequality Mechanisms}

Some participants mentioned having no access to digital technologies and were therefore unable to engage with governments online. They stated being disappointed in the Department for communicating so much online and felt left behind.

"I do not have any [digital] media because it does not interest me....So, I also do not have any of these at home: I do not have a smartphone, no iPhone, I had a laptop but I threw it away." (Male)

"But what are they doing? I feel so bad that they [the Department] just assume everyone has a computer....Belgium has 3.7 million connections to the Internet, which corresponds roughly to $70 \%$ of the people with an Internet connection, but that also corresponds to $30 \%$ who do not have it and are left behind." (Male)

Some participants are just not motivated to use digital technologies and, therefore, prefer to receive information via analogue channels. Motivation can be influenced by the digital skill level of the participant, as the quote below illustrates. Governments must create a safe and trusted environment where those who have fewer digital skills and are less confident over their skills can also feel at ease.

"The problem is that it goes in one ear and out the other. I cannot remember it and my interest is too low to make an effort for it." [computer use]. (Female)

Digital skills do not solely include technical skills, but also the ability to solve problems and to learn and think autonomously. Some participants lacked digital skills to use digital technologies in an efficient way and became frustrated. They proposed to install computers in the city hall where citizens can ask employees for help.

"An email that I have received, I am sorry, but it is too technical for me and then to have a good deal of energy to read it on screen. I really need to read it on paper." (Female)

"Or if you do not have a computer, you should be able to go to your city hall and that they explain where you can read the information [online] and that they explain to you how it works so you can find the information on your own." (Female)

Lastly, participants mentioned that the intensity of their use of digital media and their belief in digital media also influenced their decision-making process. By using digital media in an intensive way, you become more confident about your skills, which might (as aforementioned) improve your attitude towards digital media. The ones who mentioned to not believe in digital media were also those confronted with digital inequality mechanisms.

\subsubsection{Information Characteristics}

The transmitted information is rarely seen as a determinant, probably because people only see the information after they have already chosen a channel. However, we integrated them in our modified framework as information may influence citizens' second choice of a channel.

Information quality, information quantity, and comprehensibility are linked to each other as they refer to the amount and utility of the information. Comprehensibility was most mentioned. Providing a clear message in an understandable language is crucial. Nowadays, communication on spatial planning includes many concepts and legal notions citizens are not familiar with.

"What does this mean? It doesn't give you any information, unless that you can further inform yourself. But first, who does that? And second, isn't it the intention of such a poster to inform people so they already know what will happen?" (Male)

When a planning project is nearby, citizens want to receive information via more personal and/or local channels because the information has a direct impact on them (proximity level). When the project is more general or further away, they do not expect to be personally informed.

"If the streets are going to be changed on the other side of the city, I don't have to be personally informed. If I can just read it in the municipal information sheet, that is enough." (Female)

"Local television for things happening in our city. But when they are going to build a football stadium, then, of course, national television." (Male)

However, most participants lean towards local channels in general, as they are often the most relevant for them compared to non-local government channels (level of governance). Information on spatial planning should, therefore, use both local and national channels, especially for social media as our participants reported preferring local social media channels.

"I wouldn't follow the social media channels of the Department of Environment and Spatial Development because the information they provide is so wideranging." (Female)

\subsection{Digital Communication by Default for Spatial Planning in Flanders?}

In this section, we will describe how our participants perceived a digital-by-default strategy, and what conse- 
quences this might have for communication channels of spatial planning. Based on the previous quotations, we can identify two camps in general.

The first camp emphasises the need for more digitised communication as it would significantly increase ease of use. They even proposed new tools for spatial planning, such as a mobile application that signals and informs you when you are physically close to a planning project, the ability to look into the plans of the works online, etc. These tools contribute to user-friendliness as they inform citizens at an earlier stage and wherever and whenever they want it. Today, the Department already uses digital technologies in its communication strategy, but it remains very top-down, allowing no real interactions between citizens and government. Nevertheless, our respondents mentioned that they want to participate and interact more.

The second camp expresses concerns over the continuing digital strategy of Flemish policy departments. This was expected because we reached both low-level and high-level users. However, not only digitally excluded citizens raised this concern, digitally included citizens were also concerned as they feared it would push more citizens into exclusion. A multi-channel approach, consisting of both offline and online channels, is recommended to reach as many citizens as possible.

Regardless of which channels are used in spatial planning, each channel must have the possibility to unsubscribe so citizens can choose how they want to receive information or contact the Department. They want to be able to customise the communication strategy of the Department. We also saw this need for customisation in the use of hashtags and filtering systems on government websites and social media.

\section{Discussion and Conclusion}

This study has provided insights regarding channel choice for spatial planning and whether citizens embrace the move towards digital by default. It adds to the limited existing research on channel choice for spatial planning by proposing a framework of channel choice and applying it to the field of spatial planning. We conducted 10 focus groups with 86 citizens, both low-level digital users and high-level users, and evaluated the current channels of spatial planning in order to come up with recommendations. Additionally, we gathered their opinion regarding digital communication for spatial planning and particularly focused on the impact of digital exclusion in this field, a research need indicated by Evans-Cowley and Hollander (2010).

The analysis on channel choice in spatial planning shows that the most well-known channels are the poster, the municipal information sheet, the information event, and the registered letter. Some channels are not known (e.g., Belgian Offical Gazette, Twitter, participatory meeting). These results confirm the research of van Dijk et al. (2007) on e-services in the Netherlands. They found that some citizens were unfamiliar with e-services and governments should raise more awareness of these channels. All well-known channels in our focus groups are analogue, so we recommend that the Department invests in the promotion of their channels, especially social media and the diverse websites, by advertising them (e.g., promote the use of social media in a bus shelter) and by connecting them to each other (e.g., for more information visit the website).

The most decisive channel choice determinants are related to the channel itself and the given information. The look and feel, the presence, the user-friendliness, and the perceived negative image of channels were mentioned as decisive. The Department should take these determinants into account in future communication strategies in order to deal with negative perceptions of citizens. Regarding information, the message needs to be clear and self-explanatory so citizens no longer have questions. The message is best communicated via local channels of spatial planning as most of the respondents opt for local channels regardless of the level of governance of the communicated message. By doing so, a widespread distribution of the message can be ensured. In case of a close connection with the goal of the message (e.g., when works will occur in their street), information is preferably received via more personal channels (e.g., registered letter, municipal information sheet). This confirms the work of Reddick (2005a), who argues that citizens opt for contact by phone when the public institution is closer to the local level.

Situational determinants were also found to be important, especially trust in government and the effectiveness of the channels. In order to deal with the disappointment of citizens, they should be informed about their role as a citizen in the debate and within which limits they can participate in order to manage their expectations (transparency). New modes for participation via digital technologies (e.g., applications, social media) can be researched by the Department as it would enable citizens to no longer be physically present in a participatory meeting or in the city hall. However, they need to be implemented under the right conditions (e.g., enable interaction, competent staff, etc.) (Evans-Cowley \& Hollander, 2010; Trapenberg Frick, 2016; Williamson \& Ruming, 2017; Wilson, Tewdwr-Jones, \& Comber, 2017). Perhaps the most important aspect is to really engage with citizens via these technologies, as it would otherwise create more frustration and negative discussions (Schweitzer, 2014; Williamson \& Parolin, 2013; Williamson \& Ruming, 2017; Wilson et al., 2017). The Department should evaluate how they (would) use their existing and future channels to see if their strategy is in line with the specific features of these channels. A match between the type of communication and the type of channel must be made.

Though digital inequality mechanisms were mentioned less in the focus groups, their influence should not be underestimated. A digital-by-default strategy is problematic, as having access to digital technologies is 
the main requirement for the use of e-services (Ebbers et al., 2007). Some of our participants were unable to use e-services of spatial planning because they lacked the means to go online. However, as mentioned by our respondents, other issues also come into play, such as skills, motivations, use, and desires. These issues are assumed to have a major impact on the perceived satisfaction of e-services (Ebbers et al., 2016). To promote the use of eservices in spatial planning, the Department should limit problems of access, skills, motivation, etc. by investing in computer access in the city hall and providing assistance for those in need. Another recommendation is to collaborate with e-inclusion intermediaries and set up low-level and bottom-up programmes that support citizens in their use of e-government services and strengthen their confidence and autonomy of use.

The question related to the perception of citizens towards digital communication in spatial planning made it clear that most citizens were positive about it, while others were definitely not. The Department should further improve existing digital channels and explore new ways of interacting with citizens online, while also investing in analogue channels to ensure no citizen is left out of the conversation as they too are entitled to public information. This multi-channel approach might be a solution to deal with digital inequalities (Kleinhans et al., 2015; Wilson et al., 2017). We acknowledge this, but add that the multi-channel approach of the Department may not be seen as an extra element and should be part of their wider communication strategy.

Since our research is a case study, further work should be carried out to see if our findings on channel choice are also applicable to other public authorities. Additionally, they should also consider the role of income, race, and ethnicity, as this was now lacking in our study. As our study was limited to the existing channels in spatial planning and given the focus on the use of digital technologies in spatial planning, further projects can explore channel choice of e-services and map user requirements in order to improve existing and future digital channels.

\section{Acknowledgements}

We would like to acknowledge the Department of Environment and Spatial Development and the Department of Public Governance and the Chancellery of the Flemish Government for funding the project and our respondents for participating.

\section{Conflict of Interests}

The authors declare no conflict of interests.

\section{References}

Afzalan, N., \& Evans-Cowley, J. (2015). Planning and social media: Facebook for planning at the neigh- bourhood scale. Planning Practice \& Research, 30(3), 270-285.

Aizen, I. (1991). The theory of planned behavior. Organizational Behavior and Human Decision Processes, 50(2), 179-211.

Al-Hujran, O., Al-Debei, M. M., Chatfield, A., \& Migdadi, M. (2015). The imperative of influencing citizen attitude toward e-government adoption and use. Computers in Human Behavior, 53, 189-203.

Almuwil, A., Weerakkody, V., \& El-Haddadeh, R. (2011). A conceptual study of the factors influencing $e$ inclusion. Paper presented at the European, Mediterranean \& Middle Eastern conference on information systems, Athens, Greece.

Anthopoulos, L., Reddick, C. G., Giannakidou, I., \& Mavridis, N. (2016). Why e-government projects fail? An analysis of the Healthcare. gov website. Government Information Quarterly, 33(1), 161-173.

Bagozzi, R. P. (2007). The legacy of the technology acceptance model and a proposal for a paradigm shift. Journal of the Association for Information Systems, 8(4), 244-254.

Criado, J. I., Sandoval-Almazan, R., \& Gil-Garcia, J. R. (2013). Government innovation through social media. Government Information Quarterly, 30(4), 319-326.

Daft, R. L., \& Lengel, R. H. (1986). Organizational information requirements, media richness and structural design. Management Science, 32(5), 554-571.

Davis, F. D. (1989). Perceived usefulness, perceived ease of use, and user acceptance of information technology. MIS Quarterly, 13(3), 319-340.

Dugdale, A., Daly, A., Papandrea, F., \& Maley, M. (2005). Accessing e-government: Challenges for citizens and organizations. International Review of Administrative Sciences, 71(1), 109-118.

Ebbers, W. E., Jansen, M. G. M., \& van Deursen, J. A. M. (2016). Impact of the digital divide on e-government: Expanding from channel choice to channel usage. Government Information Quarterly, 33(4), 685-692.

Ebbers, W. E., Pieterson, W. J., \& Noordman, H. N. (2007). Electronic Government: Rethinking channel management strategies. Government Information Quarterly, 25(2), 181-201.

Ertiö, T.-P. (2015). Participatory apps for urban planningspace for improvement. Planning Practice \& Research, 30(3), 303-321.

Evans-Cowley, J., \& Hollander, J. (2010). The new generation of public participation: Internet-based participation tools. Planning Practice \& Research, 25(3), 397-408.

Federale Overheidsdienst Economie, K. M. O., Middenstand en Energie. (2017). Barometer van de informatiemaatschappij 2017 [Barometer of the information society 2017] (D/2017/2295/19). Brussels, Belgium: FOD Economie, K.M.O., Middenstand en Energie.

Fishbein, M., \& Aizen, I. (1975). Belief, attitude, intention 
and behavior: An introduction to theory and research. Reading, MA: Addison-Wesley.

Gil-Garcia, J. R., \& Martinez-Moyano, I. J. (2007). Understanding the evolution of e-government: The influence of systems of rules on public sector dynamics. Government Information Quarterly, 24(2), 266-290.

Glaser, B. G., \& Strauss, A. L. (1967). The discovery of grounded theory: Strategies for qualitative research. London: Aldine Transaction.

Hansson, K., Belkacem, K., \& Ekenberg, L. (2015). Open government and democracy: A research review. Social Science Computer Review, 33(5), 540-555.

Harrison, T. M., \& Sayogo, D. S. (2014). Transparency, participation, and accountability practices in open government: A comparative study. Government Information Quarterly, 31(4), 513-525.

Helsper, E. J. (2012). A corresponding fields model for the links between social and digital exclusion. Communication Theory, 22(4), 403-426.

Helsper, E. J., \& Reisdorf, B. C. (2013). A quantitative examination of explanations for reasons for internet nonuse. Cyberpsychology, Behavior, and Social Networking, 16(2), 94-99.

Hung, S., Chang, C., \& Kuo, S. (2013). User acceptance of mobile e-government services: An empirical study. Government Information Quarterly, 30(1), 33-44.

Kleinhans, R., van Ham, M., \& Evans-Cowley, J. (2015). Using social media and mobile technologies to foster engagement and self-organization in participatory urban planning and neighbourhood governance. Planning Practice \& Research, 30(3), 237-247.

Laenens, W., Vanderstraeten, E., Braet, O., Mariën, I., \& Van den Broeck, W. (2017). Vernieuwing van regelgeving in het kader van openbare onderzoeken en participatie bij ontwikkeling van ruimtelijk beleid binnen het toepassingsgebied van het verdrag van Aarhus (eindrapport. Bestek nr. RV-AJB/16/04.) [Renewal of regulations in the context of public inquiries and participation for the development of spatial policy within the scope of the Aarhus Convention (Final report: RV-AJB/16/04)]. Brussels, Belgium: imecSMIT, Vrije Universiteit Brussel.

Lourenço, R. P. (2015). An analysis of open government portals: A perspective of transparency for accountability. Government Information Quarterly, 32(3), 323-332.

Mariën, I., \& Baelden, D. (2015). 8 Profielen van Digitale Ongelijkheden (onderzoeksrapport voor het federale onderzoeksproject IDEALiC.be) [8 Profiles of Digital Inequalities (research report for the federal research project IDEALiC.be)]. Brussels: belspo.

Mariën, I., \& Vleugels, C. (2011). Van digitale kloof naar digitale inclusie: Naar een duurzame ondersteuning van e-inclusie initiatieven in Vlaanderen [From digital divide to digital inclusion: Towards a sustainable support of e-inclusion initiatives in Flanders.] Tijdschrift voor communicatiewetenschap, 39(4), 104-119.

Meijer, A. J., \& Torenvlied, R. (2014). Social media and the new organization of government communications: An empirical analysis of Twitter usage by the Dutch police. The American Review of Public Administration, 46(2), 143-161.

Mergel, I., \& Bretschneider, S. I. (2013). A three-stage adoption process for social media use in government. Public Administration Review, 73(3), 390-400.

Ohme, J. (2014). The acceptance of mobile government from a citizens' perspective: Identifying perceived risks and perceived benefits. Mobile Media \& Communication, 2(3), 298-317.

Pieterson, W. J. (2009). Channel choice. Citizens' channel behavior and public service channel strategy (Published Doctoral dissertation). University of Twente, Enschede, The Netherlands.

Pieterson, W. J. (2010). Citizens and service channels: Channel choice and channel management implications. International Journal of Electronic Government Research, 6(2), 37-53.

Pieterson, W. J., \& Ebbers, W. E. (2008). The use of service channels by citizens in the Netherlands: Implications for multi-channel management. International Review of Administrative Sciences, 74(1), 95-110.

Pieterson, W. J., \& van Dijk, J. (2007). Channel choice determinants: An exploration of the factors that determine the choice of a service channel in citizeninitiated contacts. In J. B. Cushing \& T. A. Pardo (Eds.), Proceedings of the 8th annual international digital government research conference: Bridging disciplines \& domains (pp. 148-154). Philadelphia, PA: Digital Government Society of North America.

Plattfaut, R., Kohlborn, T., Hofmann, S., Beverungen, D., Niehaves, B., Räckers, M., \& Becker, J. (2013). Unravelling (e-)government channel selection: A quantitative analysis of individual customer preferences in Germany and Australia. In J. Sprague H. Ralph (Eds.), Proceedings of the 2013 46th Hawaii international conference on system sciences (pp. 1983-1991). Washington, DC: IEEE Computer Society.

Prins, J. E. J. (2001). Electronic government. Variations on a concept. In J. E. J. Prins (Ed.), Designing egovernment. On the crossroads of technological innovation and institutional change (pp. 1-5). The Hague: Kluwer Law International.

Reddick, C. G. (2005a). Citizen-initiated contacts with government: Comparing phones and websites. Journal of E-Government, 2(1), 27-53.

Reddick, C. G. (2005b). Citizen interaction with egovernment: From the streets to servers? Government Information Quarterly, 22(1), 38-57.

Reddick, C. G., \& Anthopoulos, L. (2014). Interactions with e-government, new digital media and traditional channel choices: Citizen-initiated factors. Transforming Government: People, Process and Policy, 8(3), 398-419.

Reddick, C. G., \& Turner, M. (2012). Channel choice and public service delivery in Canada: Comparing egovernment to traditional service delivery. Govern- 
ment Information Quarterly, 29(1), 1-11.

Rogers, E. M. (2003). Diffusion of innovations (3rd ed.). New York, NY: Free Press.

Sandelowski, M. (1995). Sample size in qualitative research. Research in Nursing \& Health, 18(2), 179-183.

Sanders, K., \& Canel, M. J. (2013). Introduction: Mapping the field of government communication. In K. Sanders \& M. J. Canel (Eds.), Government communication. Cases and challenges (pp. 1-26). London: Bloomsbury Academic.

Schweitzer, L. (2014). Planning and social media: A case study of public transit and stigma on Twitter. Journal of the American Planning Association, 80(3), 218-238.

Stewart, D. W., \& Shamdasani, P. N. (1990). Focus groups: Theory and practice (1st ed.). Thousand Oaks, CA: Sage Publications.

Trapenberg Frick, K. (2016). Citizen activism, conservative views \& mega planning in a digital era. Planning Theory \& Practice, 17(1), 93-118.

van Deursen, A. J. A. M., van Dijk, J. A. G. M., \& Ebbers, W. E. (2006). Why e-government usage lags behind: Explaining the gap between potential and actual usage of electronic public services in the Netherlands. In M. A. Wimmer, H. J. Scholl, A. Grönlund, \& K. Viborg Andersen (Eds.), Electronic government: 5th international conference, EGOV 2006 (pp. 269-280). Berlin: Springer.

van Dijk, J. A. G. M. (2006). The network society. Social aspects of new media (2nd ed.). London, Thousand Oaks and New Delhi: Sage.

van Dijk, J. A. G. M., Pieterson, W., van Deuren, A., \& Ebbers, W. (2007). E-services for citizens: The Dutch usage case. In M.A. Wimmer, H. J. Scholl, \& A. Grönlund (Eds.), EGOV 2007-Proceedings of the 6th international conference on electronic government (pp. 155-166). Berlin: Springer-Verlag.
Vanhaelewyn, B., \& De Marez, L. (2017). imec. Digimeter 2017. Measuring digital media trends in Flanders. Leuven: imec.

Venkatesh, V., \& Davis, F. D. (2000). A theoretical extension of the technology acceptance model: Four longitudinal field studies. Management Science, 46(2), 186-204.

Venkatesh, V., Morris, M. G., Davis, G. B., \& Davis, F. D. (2003). User acceptance of information technology: Toward a unified view. MIS Quarterly, 27(3), 425-478.

Verdegem, P., \& Verleye, G. (2009). User-centered egovernment in practice: A comprehensive model for measuring user satisfaction. Government Information Quarterly, 26(3), 487-497.

Wijnhoven, F., Ehrenhard, M., \& Kuhn, J. (2015). Open government objectives and participation motivations. Government Information Quarterly, 32(1), 30-42.

Williamson, W., \& Parolin, B. (2013). Web 2.0 and social media growth in planning practice: A longitudinal study. Planning Practice and Research, 28(5), 544-562.

Williamson, W., \& Ruming, K. (2017). Urban consolidation process and discourses in Sydney: Unpacking social media use in a community group's media campaign. Planning Theory \& Practice, 18(3), 428-445.

Wilson, A., Tewdwr-Jones, M., \& Comber, R. (2017). Urban planning, public participation and digital technology: App development as a method of generating citizen involvement in local planning processes. Environment and Planning B: urban Analytics and City Science, 1-17. https://doi.org/10.1177 $\% 2 F 2399808317712515$

Zakareya, E., \& Zahir, I. (2005). E-government adoption: Architecture and barriers. Business Process Management Journal, 11(5), 589-611.

\section{About the Authors}

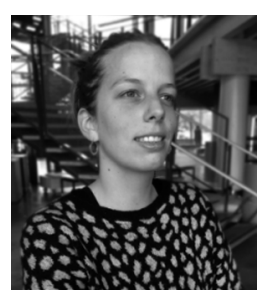

Willemien Laenens is a Researcher at Vrije Universiteit Brussel (imec-SMIT). Her main topics of interest are digital inclusion, digital exclusion mechanisms, and smart cities. In her research on the use of digital media and digital services, she particularly focuses on the involvement of vulnerable social groups, as their voices are often not heard. Her current research project, PAR4-B, focuses on the development of an e-inclusive Smart City masterplan for Brussels by bringing together several stakeholder groups, including vulnerable social groups.

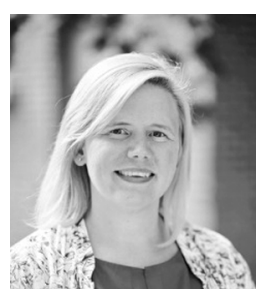

Wendy Van den Broeck is an Assistant Professor in communication studies at Vrije Universiteit Brussel and head of living labs within the imec-smit research group. Her main research expertise is in user studies in the domain of personalised and immersive media and smart education. She is also specialised in research methodology and focuses mainly on living lab research and user research methods. She is currently involved in the set-up of the smart education Databuzz, aimed at enhancing youngsters' data literacy skills. 


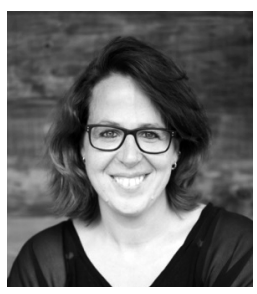

Ilse Mariën is a Senior Researcher at imec-SMIT, a research institution attached to the Vrije Universiteit Brussel (VUB). Currently, Ilse is leading IDEALiC, a project that focuses on setting the future scene of e-inclusion and PAR4-B that consists in developing e-inclusive smart city policies via participatory action research. Over the years Ilse has developed extensive expertise on e-inclusion theories and policies, research with vulnerable groups, and innovative, interactive, participatory, and action-oriented research methods. 